\title{
Detection of Methicillin Resistant Staphylococcus aureus in Dairy Products and Anterior Nares of Dairy Workers
}

\author{
Ranjana K.C ${ }^{1}$, Ganga Timilsina ${ }^{2}$, Supriya Sharma ${ }^{1 *}$ \\ ${ }^{1}$ Central Department of Microbiology, Tribhuvan University, Kirtipur, Kathmandu, Nepal \\ ${ }^{2}$ Dairy Development Corporation Balaju unit, Kathmandu, Nepal
}

${ }^{*}$ Corresponding author: Ms. Supriya Sharma, Central Department of Microbiology, Tribhuvan University, Kirtipur, Kathmandu, Nepal; E-mail: suprisharma@hotmil.com

\section{ABSTRACT}

Objectives: To isolate methicillin resistant Staphylococcus aureus (MRSA) from anterior nares of dairy workers and dairy products and assess the antibiotic susceptibility pattern of the isolates.

Methods: Swab samples collected from anterior nares of dairy workers and dairy product (butter) were inoculated into mannitol salt agar and incubated at $37^{\circ} \mathrm{C}$ for 24 hours. Identification was done based on colony characteristics, Gram's staining, catalase, oxidase and coagulase test. Antibiotic susceptibility testing was done by modified Kirby Bauer disc diffusion method. MRSA was confirmed by using cefoxitin disc.

Results: A total of 109 S. aureus (98 from dairy workers and 11 from butter samples) were isolated. Out of them 32 MRSA were isolated from dairy workers and 4 from butter samples. The association between age group and MRSA was found insignificant $(\mathrm{p}=0.115)$. The association of MRSA between male and female workers was found significant $(>0.05)$. About $86 \%$ of the MRSA isolates were susceptible to Gentamicin ( $86.11 \%)$ followed by Ciprofloxacin $(77.78 \%)$.

Conclusion: Detection of MRSA among dairy workers and dairy products warrants proper handling and adequate control measures to prevent transmission of MRSA from dairy industry.

Key words: MRSA, dairy products, dairy workers, carriage

\section{INTRODUCTION}

Staphylococcus aureus is considered to be one of the leading causes of food borne illness. Milk, dairy products and meats are often contaminated with this bacterium. Foodstuff contamination may occur directly from infected food producing animals or may result from poor hygiene during production processes or the retail and storage of foods, since humans may carry the microorganisms (Hennekinne et al. 2010). S. aureus colonizes skin and mucosa of humans and animals, with nasal carriage rates between $30 \%$ and 50\% among the adult human population (Sakr et al. 2018). While colonization of the anterior nares is usually asymptomatic, it serves as a reservoir for the spread of the organism. Carries are at increased risk to develop bacteremia which in $80 \%$ of cases is caused by the strain colonizing their nares (Hassoun et al. 2017). The rapid emergence of antibiotic resistance among $S$. aureus is also known to play a crucial role in the epidemiology of

Date of Submission: October 25, 2019

Published Online: December, 2019 staphylococcal infections (Wertheim et al. 2005).

Methicillin resistant $S$. aureus (MRSA) has become an increasingly important and serious public health concern due to the morbidity, mortality and cost that is associated with these infections annually. Once exposed to MRSA, animals may become colonized, and serve as reservoirs to transmit the infection to other animals or humans. Data has shown that with human to animal transmission, there is a possibility that until the animal is free of infection, re-transmission from the animal and subsequent human to human transmission can occur (American Veterinary Medical Association 2009). Therefore, this study aims to isolate MRSA from anterior nares of dairy workers and dairy products and assess the antibiotic susceptibility pattern of the isolates.

\section{MATERIALS AND METHODS}

This descriptive cross-sectional study was carried out

Date of Acceptance: December 1, 2019

DOI: https:/ / doi.org/10.3126/tujm.v6i0.26585 
in the quality control laboratory of Dairy Development Corporation, Balaju, Kathmandu, Nepal. A total of 109 samples from dairy workers and dairy products were investigated.

\section{Sample collection and processing}

Samples were collected aseptically from nasal swabs of both noses from dairy workers of different working units. The samples were also collected from butter samples by means of sterile cotton swab in separate sterile screw-capped test-tube. All the samples were labeled properly and processed in the laboratory as soon as possible. In case of delay, samples were stored at refrigerator $\left(2-8^{\circ} \mathrm{C}\right)$.

Each sample was inoculated into mannitol salt agar plates and incubated at $37^{\circ} \mathrm{C}$ for 24 hours. Identification of S.aureus was done based on colony characteristics, Gram's staining, catalase, oxidase and coagulase test (Chakraborty 2011). All identified S. aureus isolates were processed for antibiotic susceptibility testing by modified Kirby Bauer disc diffusion method as recommended by Clinical Laboratory Standards Institution (CLSI, 2013). Antibiotic discs (Hi Media
Laboratories, Pvt. Limited, India) such as ciprofloxacin $(5 \mu \mathrm{g})$, clindamycin $(2 \mu \mathrm{g})$, gentamicin $(10 \mu \mathrm{g})$, penicillin $\mathrm{G}(10 \mathrm{U})$, teicoplanin $(10 \mu \mathrm{g})$ were used for antibiotic susceptibility tests.

The isolates showing zone of inhibition of $\leq 21 \mathrm{~mm}$ around cefoxitin disc $(30 \mu \mathrm{g})$ were considered as MRSA (CDC 2019). Data were analyzed by IBM SPSS statistics 21 software. Frequency and percentage for descriptive and Chi Square test with cross tab for inferential statistics were used.

\section{RESULTS}

Altogether 109 S. aureus were isolated of which 98 $(89.90 \%)$ were from dairy workers and 11 (10.10\%) from dairy products. Out of 98 isolates recovered, $63.26 \%(n=62)$ were from male and $36.34 \%(n=36)$ were from female workers. Similarly, 7 (63.63\%) of $S$. aureus were isolated from plain butter (exported) and 4 strains $(36.36 \%)$ were from table butter.

The maximum numbers of MRSA were isolated from dairy workers of age group 40-49 years followed by 3039 years. However, the number of MRSA and age was not statistically significant (Table 1 ).

Table 1: Distribution of MRSA among different age groups of dairy workers

\begin{tabular}{cccc}
\hline Age in years & No. of S. aureus & MRSA N (\%) & p- value* \\
\hline $20-29$ & 8 & $2(25.00)$ & \\
$30-39$ & 28 & $11(39.28)$ & 0.115 \\
$40-49$ & 47 & $15(31.91)$ & \\
$50-59$ & 15 & $4(26.67)$ & \\
\hline Total & 98 & 32 & \\
\hline
\end{tabular}

${ }^{*}$ p-value calculated using chi-square test

MRSA was isolated more from male workers as compared to female workers (Table 2).

Table 2: Distribution of MRSA among different gender of dairy workers

\begin{tabular}{lccc}
\hline Gender of workers & No. of S. aureus & MRSA N (\%) & p- value* \\
\hline Male & 56 & $20(35.71)$ & 0.001 \\
Female & 42 & $12(28.57)$ & \\
\hline Total & 98 & 32 & \\
\hline
\end{tabular}

*p-value calculated using chi-square test

Antibiotic susceptibility pattern showed that most followed by Ciprofloxacin (Table 3). of the MRSA isolates were susceptible to Gentamicin

Table 3: Antibiotic susceptibility pattern of MRSA isolates

\begin{tabular}{lcc}
\hline Antibiotics used & Susceptible N (\%) & Resistant N (\%) \\
\hline Ciprofloxacin & $28(77.78)$ & $8(22.22)$ \\
Clindamycin & $26(72.22)$ & $10(27.78)$ \\
Gentamicin & $31(86.11)$ & $5(13.89)$ \\
Penicillin G & $24(66.67)$ & $12(33.33)$ \\
Teicoplanin & $27(75.00)$ & $9(25.00)$ \\
\hline
\end{tabular}




\section{DISCUSSION}

Isolation of 109 strains of $S$. aureus from dairy workers and dairy sample i.e. table butter and plain butter (exported) in our study is similar to that conducted by Crago et al. (2014). Andre et al. (2008) found that $75 \%(3 / 4)$ of the investigated persons were colonized with S. aureus. Huber et al. (2010) found that a nasal carriage rate was approximately $27 \%$ in healthy adult populations. Two studies with pre-clinical medical students showed that $35.2 \%$ and $29 \%$ were S. aureus nasal carriers (Bischoff et al. 2005). Our result is consistent with these findings.

Similarly, 11 strains of $S$. aureus were detected from butter sample which was $10.10 \%$ of total isolates. Among them 7 strains (63.63\%) were isolated from plain (exported) butter whereas 4 strains (36.36\%) were from table butter. Due to predominantly manual handling during butter packaging, contamination with S. aureus might occur. Highest number of MRSA in our study were found at the age of range of range 40-49 years. However, the association between age groups and MRSA was found statistically insignificant which signifies that presence of MRSA does not depend on the age group. The detection of MRSA in workers and butter suggests that healthy human could play a role in the spread of MRSA among animals, workers, and the food environment (Crago et al. 2014).

Livestock derived food product that could lead to MRSA food intoxication or serve as vehicle for MRSA transmission is raw milk, when contaminated raw milk is used for the production of cheese. This was reported in Italy, where two MRSA strains of unknown origin were found in dairy cheese products (Normanno et al. 2007). As these strains were found to harbor genes for expression of common staphylococcal enterotoxins, they had the potential to cause food poisoning (Normanno et al. 2007).

The major limitation of our study is that this we have not correlated the strains isolated from dairy workers and dairy product. Further studies should be done to correlate the strains upto sequence level.

\section{CONCLUSION}

Detection of MRSA among dairy workers and dairy products warrants proper handling and adequate control measures to prevent transmission of MRSA from dairy industry.

\section{ACKNOWLEDGEMENTS}

The authors acknowledge the concerned persons at Dairy Development Corporation (DDC) Balaju unit, Kathmandu, Nepal and Central Department of Microbiology, Tribhuvan University, Kirtipur, Kathmandu, Nepal for their contributions.

\section{CONFLICT OF INTEREST}

The authors declare no conflict of interest.

\section{REFERENCES}

Andre MC, Campos MR, Borges LJ, Kipnis A, Pimenta FC and Serafini AB (2008). Comparison of Staphylococcus aureus Isolates from Food Handlers, Raw Bovine Milk and Minas Frescal Cheese by Antibiogram and Pulsed-Field Gel Electrophoresis Following SmaI Digestion. Food Contrl 19: 200-207.

Bischoff WE, Wallis ML, Tucker KB, Reboussin BA and Sherertz RJ (2004). Staphylococcus aureus nasal carriage in a student community: prevalence, clonal relationships, and risk factors. Infect Control Hosp Epidemiol 25: 485-91.

Centres for Diseases Control (CDC) (2019). Methicillin Resistant Staphylococcus aureus. URL: https:// www.cdc.gov/mrsa/lab/index.html

Chakraborty SP, Mahapatra SK and Roy S (2011). Biochemical characters and antibiotic susceptibility of Staphylococcus aureus isolates. Asian Pac J trop biomed 1: 212-216.

Clinical and Laboratory Standard Institute (2013). $\mathrm{M}_{100}-\mathrm{S}_{23 \mathrm{p}}$ erformance standards for antimicrobial susceptibility testing; twenty-third informational supplement. CLSI Wayne, USA 33: 1-199.

Crago B, Ferrato C, Drews SJ, Svenson LW, Tyrrell G and Louie M (2012). Prevalence of Staphylococcus aureus and methicillin resistant $S$. aureus (MRSA) in food samples associated with foodborne illness in Alberta, Canada from 2007 to 2010. F Microbiol 32: 202-205.

Hassoun A, Linden PK and Friedman B (2017). Incidence, prevalence, and management of MRSA bacteremia across patient populations-a review of recent developments in MRSA management and treatment. Crit Care 21: 211-221.

Huber H, Koller S, Giezendanner N, Stephan R and 
Zweifel C (2010). Prevalence and characteristics of meticillin resistant Staphylococcus aureus in humans in contact with farm animals, in livestock, and in food of animal origin, Switzerland, 2009. Euro Surveill 15: 19542.

Normanno G, Corrente M, La Salandra G, Dambrosio A, Quaglia NC and Parisi (2007). Methicillinresistant Staphylococcus aureus (MRSA) in foods of animal origin product in Italy. Int J Food Microbiol 117: 219-222.

Sakr A, Bregeon F, Mege JL, Rolain JM and Blin O (2018). Staphylococcus aureus basal colonization: An update on mechanisms, epidemiology, risk factors and subsequent infections. Front Microbiol 9: 2419-2434. 